\title{
High and low temperature device with Non-magnetic based on PID control
}

\author{
Xiaofei Wang ${ }^{1}$, \\ ${ }^{1}$ CCTEG Xi'an Research Institute, Xi'an, Shaanxi, China
}

\begin{abstract}
There are not a single influencing factors in the temperature drift correction test of tilt measuring products. In order to solve this problem, by analyzing and calculating the influencing factors, a non-magnetic height suitable for temperature drift correction of tilt measuring products is designed. Low temperature device, this device is based on PID control, which has the advantages of precise temperature control, rapid heating, and good temperature stability.
\end{abstract}

\section{Preface}

Inclination products used in underground coal mines and petroleum directional drilling, generally contain acceleration sensors and magnetic sensors. The measurement principle is based on the earth's gravitational field and magnetic field as the reference frame, and the acceleration sensors and magnetic sensors are used to calculate the measurement. The azimuth angle, inclination angle, and tool face angle of the oblique probe tube, are used to achieve the purpose of guiding directional drilling and improve the first-time success rate of directional drilling.

The measurement accuracy of inclinometer products is affected by many factors such as sensor measurement accuracy, sensor temperature drift, signal data processing error, etc. ${ }^{[1]}$. Signal data processing errors mainly include errors caused by transmission and recording and errors caused by imperfect data processing. In recent years, microelectronics technology has developed rapidly, and the technical level has become more mature. It uses highperformance $\mathrm{CPU}$ and $\mathrm{A} / \mathrm{D}$ conversion chips. Under the control of the software, the error can be maintained low order of magnitude ${ }^{[2]}$. Therefore, the error of inclinometer products is mainly the temperature drift error caused by high and low temperature conditions.

The temperature drift test requires a high and low temperature test environment. At present, the high and low temperature test environment on the market is an integrated structure of the test body and the control body. Factors such as the cooling and heating system, power supply system, and stainless steel housing in the control body will cause electromagnetic interference. In the case of electromagnetic interference, due to the particularity of the inclinometer, there is a certain error in the output of the magnetic sensor, which destroys the principle of unity of influencing factors in the high and low temperature test, and affects the accuracy of temperature drift compensation. Therefore, it is particularly important to study the high and low temperature test environment suitable for inclinometer products.

\section{The design principle of high and low temperature test environment with non- magnetic}

\subsection{Principle of non-magnetic test}

On the earth, there is no absolute non-magnetic, only relative "non-magnetic" or low magnetic. The "nonmagnetic" referred to in this topic also refers to the object to be measured. Ferromagnetic devices will definitely be used in high and low temperature test chambers. As long as the test environment has a single influencing factor, and the magnetic substances in the test environment have no effect on the output of the device, or the effect is negligible, we consider this test box as a "non-magnetic" environment.

Because the control box contains a large amount of ferromagnetic objects, placing the measured object in it will inevitably interfere with the magnetic sensor, which will result in multiple factors affecting the test environment and affect the analysis accuracy of the results. In order to solve this problem, this subject separates the test box from the control box. All parts related to the test box except the control box are made of non-magnetic materials. Ensure the principle of unity of factors affecting the test environment.

The test box used to place the test object is made of non-magnetic material. Because the test box is a certain distance from the control box, and the air supply system and return air system are made of non-magnetic materials, the test box is made of non-magnetic materials. Measure the object away from electromagnetic interference. The relatively non-magnetization that forms the test environment.

\footnotetext{
*Corresponding author: Wangxiaofei@cctegxian.com
} 


\subsection{Non-magnetic high and low temperature test environment design}

Inclination instruments need to perform full-space azimuth control on the calibrated calibration table during angle calibration. Similarly, the original intention of the design of high and low temperature test environment with non-magnetic is to solve the problem that the inclinometer cannot perform temperature calibration. Therefore, the non-magnetic high and low temperature test device suitable for inclinometer products requires the tested inclinometer to be far away from electromagnetic interference, that is, it needs to meet the requirement of "non-magnetic". At the same time, it is also required that the tested inclinometer can perform multi-angle angle control during high and low temperature tests. Therefore, in the high and low temperature test environment with non-magnetic, the traditional integrated high and low temperature test structure is separated, and the control box is kept away from the test body, so as to achieve the effect of keeping the measured object away from electromagnetic interference. In addition, the nonmagnetic test tube must be Place it on the calibration frame to control the angle to realize the multi-angle output test of the inclinometer at different temperatures, determine the temperature drift calibration algorithm according to the output results, and finally realize the temperature drift calibration of the tilt sensor and the azimuth sensor.

\subsection{Selection of non-magnetic materials}

\subsubsection{Selection of duct material}

In the air circulation structure, since the air pipe is directly connected to the test tube, the air pipe must be made of non-magnetic high-temperature resistant materials; in actual use, the air pipe will be twisted to a certain degree due to the need for angle control. The commonly used non-magnetic beryllium copper or polytetrafluoroethylene material is directly used, and the air pipe made is expensive and cannot be twisted, which has certain restrictions on the angle control of the test tube. Commonly used large-bend ventilation pipes include PVC type, aluminum foil metal type, high temperature vulcanization type, nylon cloth type, and polyurethane type. As shown in Table 1, the performance parameters of common ventilation pipes. The first four materials, PVC and nylon fabrics have lower temperature resistance, and the other three have higher temperature resistance. However, the reinforcing ribs of aluminum foil metal type and nylon fabric type are generally metal materials, which have an impact on sensitive magnetic instruments. As shown in Figure 2, the system is made of polyurethane material, the reinforcing ribs are plastic ribs, can withstand a temperature of -50 to $200^{\circ} \mathrm{C}$, and have a good degree of curvature, which can meet the angle conversion in allround space.
Table 1 Commonly used air duct performance parameters

\begin{tabular}{|l|l|l|l|l|l|}
\hline & PVC & $\begin{array}{l}\text { Alumi } \\
\text { num } \\
\text { foil } \\
\text { metal } \\
\text { tempera } \\
\text { ture } \\
\text { vulcani } \\
\text { zation }\end{array}$ & $\begin{array}{l}\text { High } \\
\text { fabric }\end{array}$ & $\begin{array}{l}\text { Polyur } \\
\text { ethane }\end{array}$ \\
\hline $\begin{array}{l}\text { temperature } \\
\text { range }\end{array}$ & $\begin{array}{l}0 \sim \\
80\end{array}$ & $\begin{array}{l}-70 \sim \\
400\end{array}$ & $\begin{array}{l}-70 \sim \\
300\end{array}$ & $\begin{array}{l}- \\
50 \sim 12 \\
0\end{array}$ & $\begin{array}{l}\text { 50 20 } \\
0\end{array}$ \\
\hline $\begin{array}{l}\text { Reinforcing } \\
\text { rib material }\end{array}$ & $\begin{array}{l}\text { Iron } \\
\text { wire } \\
\text { (steel } \\
\text { wire })\end{array}$ & $\begin{array}{l}\text { Iron } \\
\text { wire } \\
\text { (steel } \\
\text { wire })\end{array}$ & $\begin{array}{l}\text { Iron } \\
\text { wire } \\
\text { (steel } \\
\text { wire) }\end{array}$ & $\begin{array}{l}\text { Iron } \\
\text { wire } \\
\text { (steel } \\
\text { wire })\end{array}$ & $\begin{array}{l}\text { Plastic } \\
\text { rib }\end{array}$ \\
\hline $\begin{array}{l}\text { Magnetic or } \\
\text { not }\end{array}$ & Y & Y & Y & Y & N \\
\hline $\begin{array}{l}\text { Easy to bend } \\
\text { or not }\end{array}$ & Y & Y & Y & Y & Y \\
\hline
\end{tabular}

\subsubsection{Selection of test tube material}

Commonly used non-magnetic materials are PTFE, beryllium copper, etc., and their performance parameters are shown in Table 2.

Table 2 Non-magnetic material performance parameters

\begin{tabular}{|l|l|l|l|l|}
\hline & $\begin{array}{l}\text { Maximum } \\
\text { working } \\
\text { temperature }\end{array}$ & $\begin{array}{l}\text { Heat } \\
\text { loss }\end{array}$ & $\begin{array}{l}\text { Price } \\
\text { (yuan/kg) }\end{array}$ & $\begin{array}{l}\text { Density } \\
(\mathrm{g} / \mathrm{cm})\end{array}$ \\
\hline $\begin{array}{l}\text { Beryllium } \\
\text { copper }\end{array}$ & 850 & Faster & 400 & 8.3 \\
\hline PTFE & 260 & Slower & 100 & 2.3 \\
\hline
\end{tabular}

It can be seen from Table 2 that although beryllium copper has good thermal stability, it is expensive, bulky, and has faster heat loss. The high temperature resistance of PTFE is $260^{\circ} \mathrm{C}$, which is sufficient to meet the high temperature requirements in the device, and the price is low, light, and thermal. The loss is relatively slow, which fully meets our requirements. Since the test tube is a rigid part and is fixed on a shelf for use, a tube made of PTFE is used.

\section{PID control system}

\subsection{The principle of PID control}

The characteristic of PID control is that it only needs to adjust the controller parameters, that is, to adjust $\mathrm{K}_{\mathrm{D}}, \mathrm{K}_{\mathrm{I}}$, and $K_{P}$ to obtain satisfactory results. The PID control system is composed of a PID controller and the controlled object. The PID controller is a linear controller. According to the control deviation formed by the set target value and the actual output value, the proportional, integral and derivative of this deviation are combined to form a control quantity, through a linear combination to control the object $^{[3]}$

The temperature of the test box is obtained by the PT100 temperature sensor through the conversion module, using the three-wire connection method ${ }^{[4]}$, which reduces the secondary circuit and contact resistance of the sensor and the power supply, and ensures the measurement accuracy ${ }^{[5]}$. 
In the process of temperature control, PID closed-loop control is used to achieve the purpose of precise temperature control. The user sets the temperature and humidity value through the computer interface, and the system uses the temperature and humidity value as an input signal to send the information to the system. Through comparison with the temperature and humidity sensor data, the error is fed back to the system through the PID system to adjust the temperature. Through continuous calibration of the temperature and humidity sensor and the set value, finally the actual temperature and humidity reach the set temperature and humidity value. Through PID continuous feedback control, a constant temperature environment in the test box is also realized. As shown in Figure 1, it is a schematic diagram of system PID control.

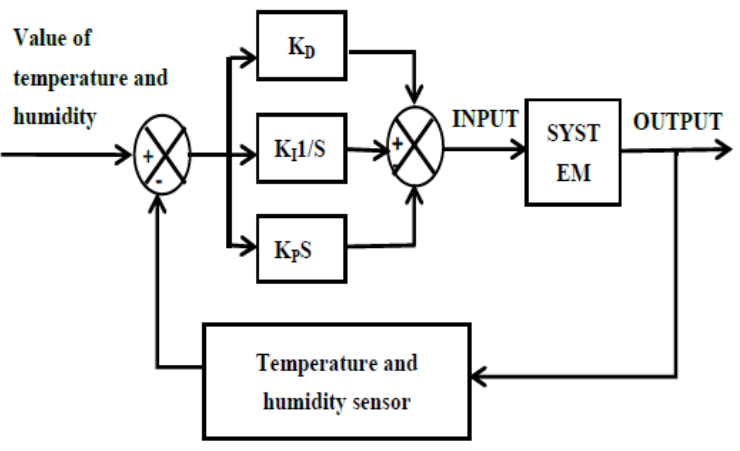

Fig. 1. Schematic diagram of system PID control

\subsection{The system of PID control}

The control box of the high and low temperature device is equipped with two quartz stone heaters and two refrigeration compressors. The relay is responsible for controlling the heater; the contactor is responsible for controlling the refrigeration compressor. After the data of the temperature sensor and the humidity sensor are converted into electrical signals, the CPU transmits the instructions to the PLC through the algorithm program, and the PLC controls the relay or contactor to control the work of the heater and the refrigerator. In order to good control the system, the user can also program the PID parameters through the upper computer. The data after the test can also be plotted on the display screen. The specific program control flowchart is shown in Figure 2.

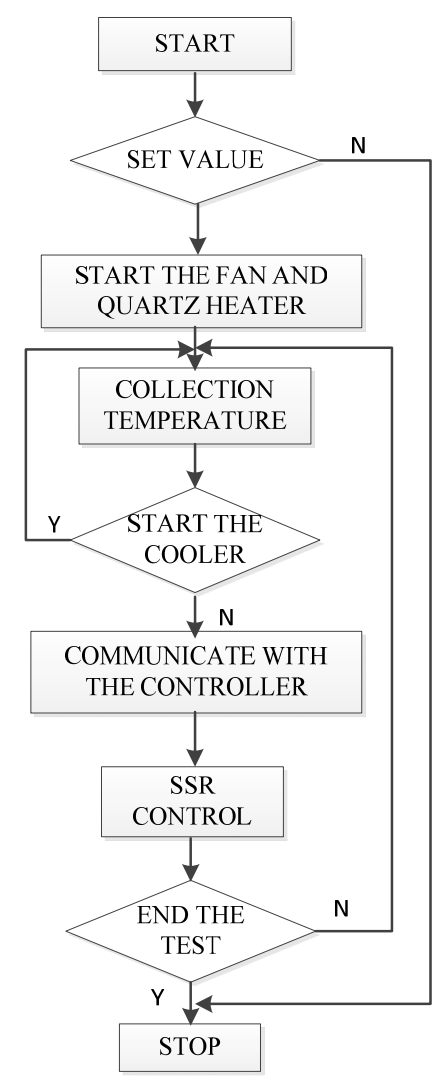

Fig. 2. Flow chart of system control program

\subsection{High and low temperature test environment with non-magnetic related parameters}

The relevant parameters of the non-magnetic high and low temperature test environment are as follows:

1. Temperature control range: $-20^{\circ} \mathrm{C}-120^{\circ} \mathrm{C}$;

2. Temperature error: $\leq \pm 1^{\circ} \mathrm{C}$;

3. Temperature uniformity: $\leq \pm 0.5^{\circ} \mathrm{C}$.

\section{Application}

The temperature drift correction test of the inclinometer is carried out with the non-magnetic high and low temperature test device. The machine runs normally, the temperature rises quickly, the temperature error is small, and the temperature is maintained in good condition. The heating rate is shown in Table 1 , and the cooling rate is shown in Table 2. Table 1 and 2 show that the heating rate is $1.8^{\circ} \mathrm{C} / \mathrm{min}$, and the cooling rate is $0.9^{\circ} \mathrm{C} / \mathrm{min}$. Temperature deviation: $\max =0.86^{\circ} \mathrm{C}, \min =0.64^{\circ} \mathrm{C}$. The temperature fluctuation is $0.03^{\circ} \mathrm{C}$.

Table 3 Experimental data of heating

\begin{tabular}{|c|c|c|c|c|}
\hline $\begin{array}{c}\text { Heating } \\
\text { rate }\end{array}$ & $\begin{array}{c}0 \rightarrow \\
10^{\circ} \mathrm{C}\end{array}$ & $\begin{array}{c}30 \rightarrow \\
40^{\circ} \mathrm{C}\end{array}$ & $\begin{array}{c}60 \rightarrow \\
70^{\circ} \mathrm{C}\end{array}$ & $\begin{array}{c}110 \rightarrow \\
120^{\circ} \mathrm{C}\end{array}$ \\
\hline $\begin{array}{c}\text { Time } \\
\text { required }\end{array}$ & $8 \mathrm{~min}$ & $5 \mathrm{~min}$ & $4.5 \mathrm{~min}$ & $4.5 \mathrm{~min}$ \\
\hline $\begin{array}{c}\text { Time } \\
\text { required }\end{array}$ & \multicolumn{4}{|c|}{$1.8^{\circ} \mathrm{C} / 1 \mathrm{~min}$} \\
\hline
\end{tabular}


Table4 Experimental data of cooling

\begin{tabular}{|c|c|c|c|c|}
\hline $\begin{array}{c}\text { Cooling } \\
\text { rate }\end{array}$ & $\begin{array}{c}10 \rightarrow 0 \\
{ }^{\circ} \mathrm{C}\end{array}$ & $\begin{array}{c}40 \rightarrow 30 \\
{ }^{\circ} \mathrm{C}\end{array}$ & $70 \rightarrow 60^{\circ} \mathrm{C}$ & $\begin{array}{c}120 \rightarrow 110 \\
{ }^{\circ} \mathrm{C}\end{array}$ \\
\hline $\begin{array}{c}\text { Time } \\
\text { required }\end{array}$ & $8 \mathrm{~min}$ & $9 \mathrm{~min}$ & $9.5 \mathrm{~min}$ & $9.5 \mathrm{~min}$ \\
\hline $\begin{array}{c}\text { Time } \\
\text { required }\end{array}$ & \multicolumn{5}{|c|}{$0.9^{\circ} \mathrm{C} / 1 \mathrm{~min}$} \\
\hline
\end{tabular}

At room temperature, the output of the inclinometer placed in the non-magnetic test tube is consistent with the output when there is no ferromagnetic interference around it, which proves that there is no electromagnetic interference in the test tube or the interference is negligible. In the case of high and low temperature tests, the angle output of the inclinometer has a single influencing factor, and this test body is suitable for temperature drift correction tests for inclinometer products.

\section{Summary}

1) Solve the problem of multiple influencing factors in the high and low temperature test of inclinometer products, and design the split structure and non-magnetic components to solve the problem of electromagnetic interference.

2) To solve the problem that the tilt measuring products cannot perform accurate angle changes in the high and low temperature cabinets, the test cabinet is designed as a cylindrical test tube and clamped on the angle conversion rack to perform multi-angle and omni-directional angle temperature drift correction test.

3) Adjust and control the temperature through PID closed-loop algorithm to make the temperature control accurate and rapid, which is conducive to the development of the test.

\section{References}

1. Zhang X.M, Gao C.H, Fan Y.R, (2002) Analysis of

2. factors affecting the measurement accuracy of digital continuous inclinometers,. Henan Petroleum, 16(5): 39-43.

3. Zhang Y.B, Meng Y.H, Wei CH.M, et al.(2010) Research on sensor signal processing technology in the inclinometer while drilling, .Journal of Kunming University of Science and Technology (Science and Technology Edition),35(2):32-35.

4. Shi Y, Feng Z.X, Research on Control Method Based on Fuzzy PID Controller (2011),1:166-172

5. Chen, AJ. Application of New Method of PID Control in High and Low Temperature Experiment Box, (2017),Computer Products and Circulation, 7:156

6. Liang J, The Design of Fuzzy Incremental PID Controller for High and Low Temperature Humidity and Heat Test Chamber (2018), Instrumentation and analysis monitoring, 2:25-28 